\title{
LA MÚSICA Y RAMÓN GAYA
}

\author{
Pedro Sanz Ayala \\ Profesor Superior de Viola, Violín y Música de Cámara. \\ Conservatorio de Música de Murcia. \\ Licenciado en Historia del Arte. \\ Violista del Cuarteto Saravasti.
}

\section{RESUMEN:}

El presente artículo trata de la importancia que tuvo la música en la vida y en la obra de Ramón Gaya: cómo influyó en la creación de su obra y cómo se refleja en ella, en su pintura, en su literatura, en su poesía. Veremos la admiración y el entusiasmo que Gaya sentía hacia la música y hacia algunas de sus principales figuras, la influencia que tuvo en su obra y la gran cantidad de escritos y pinturas con temática musical que Gaya nos legó. Gaya fue un creador y un artista completo. Pintor, escritor, ensayista, poeta...Y la música siempre estuvo presente en su vida y en su obra.

\section{PALABRAS CLAVE:}

Ramón Gaya, música, Victoria de los Ángeles, Salvador Moreno.

\begin{abstract}
:
This article deals with the importance that music had in the life and work of Ramón Gaya: how it influenced the creation of his work and how it is reflected in it, in his painting, in his literature, in his poetry. We will study the admiration and enthusiasm that Gaya felt towards music and towards some of its main figures, the influence of the music on his work and the large amount of music-themed writings and paintings that Gaya left us. Gaya was a complete creator and artist. Painter, writer, essayist, poet ... And music was always present in his life and in his work.
\end{abstract}

\section{KEYWORDS:}

Ramón Gaya, music, Victoria de los Ángeles, Salvador Moreno.

La música. ¿Por qué la música? Ramón Gaya (1910-2005) es conocido por todos por su pintura. Los que lo trataron un poco más en profundidad o aquellos que se han adentrado en su obra de un modo más amplio, saben sobradamente que también fue poeta, escritor y ensayista, y que, además de su pintura, su literatura y sus escritos 
forman una parte fundamental de su arte, de su creación. Pero ¿dónde se encuentra la música dentro de ese arte? Gaya fue un artista del Renacimiento, un artista completo, así que un creador total como él no podía dejar de lado el arte de la música.

A partir de este planteamiento, el presente artículo tiene por objetivo demostrar la importancia que la música tuvo en la vida y en la obra de Ramón Gaya. A través de sus textos y sus pinturas se analizará el entusiasmo que él sentía hacia algunas figuras de la música y el papel determinante que ésta desempeñó para la creación de su obra.

Investigar qué valor, qué papel juega la música en la obra de Gaya es sumamente revelador, ya que la música es quizás la gran olvidada dentro de su arte. En 2011 realicé una exhaustiva investigación sobre la importancia y la influencia que tuvo la música en la vida y en la obra de Ramón Gaya. Dicho trabajo fue el primero en abordar este campo de estudio ${ }^{1}$.

Las fuentes empleadas en este artículo son, por un lado, las pinturas de contenido musical de Ramón Gaya, y por otro, su obra literaria, en especial los textos en los que la música está presente. Particularmente importantes han sido tres referencias: Obra completa, publicada en 2010, que recoge por primera vez todos los escritos de Gaya en un solo volumen; Ramón Gaya de viva voz. Entrevistas (1977-1998), editada en 2007, que reúne una selección de entrevistas en las que Gaya habla en primera persona de diversos aspectos relacionados con su vida y con su obra; y Cartas de Ramón Gaya, de 1993, que presenta epístolas de Gaya destinadas a diferentes amistades.

\section{Cultura, arte y música}

Desde su infancia en Murcia, la vida de Gaya siempre estuvo rodeada de arte y cultura. Sus padres, de origen catalán, se instalaron en Murcia por motivos laborales. Salvador Gaya dibujaba y diseñaba etiquetas para botes de conservas en su taller de litografía. Era culto, ilustrado, amante de la literatura y de la música, en especial de

\footnotetext{
${ }^{1}$ Sanz, Pedro (2011). La música en la obra de Ramón Gaya (1910-2005). Trabajo Fin De Máster en Investigación Musical presentado en el Departamento de Expresión Plástica, Musical y Dinámica, de la Facultad de Educación de la Universidad de Murcia. Quiero agradecer a la tutora de dicho TFM, la doctora M. ${ }^{a}$ Esperanza Clares, cuya ayuda fue esencial para poder llevarlo a cabo. Igualmente, mostraré mi gratitud al Museo Ramón Gaya de Murcia, a su entonces director Manuel Fernández-Delgado, a todos los amigos de Gaya que me fueron mostrando su fascinante figura: Pedro Soler, Pedro Serna, Juan Ballester, José Rubio, y, de una forma muy especial, a Isabel Verdejo, Cuca para los amigos, viuda de Gaya, a la que consulté datos que nadie más podía saber, que sólo ella conocía. Ella fue fundamental para mi trabajo.
} 
Richard Wagner, lector de Tolstoi, Nietzsche y Galdós. Poseía una biblioteca que su hijo siempre tuvo a su disposición. Gaya creció en este ambiente familiar apasionado por la cultura, la música, la pintura y la literatura. Además, tuvo un hermano mayor, un pequeño violinista, Ernesto, que falleció a los siete años, apenas unos meses después de nacer Ramón. Esto le respondía a Andrés Trapiello en una entrevista en 1988:

Teniendo yo unos meses, murió un hermano mío de siete años, que era un poco un niño prodigio, pues tocaba el violín. Bueno, tocaba a Bach [...]. Mis padres no se consolaron nunca de esa pérdida, además porque mi padre era un gran aficionado a la música... Mi padre era un obrero, un litógrafo, «maquinista litógrafo» se llamaba entonces. Venía de esa tendencia de obreros litógrafos, grabadores, impresores, con una cultura que no era la de un obrero propiamente, en fin, que no era corriente en un obrero. Así que en mi casa, claro, he respirado ese ambiente desde niño. A los diez años ya me encerraba en un cuarto a leer autores españoles y extranjeros. (2007: 260)

Como podemos observar, la música siempre estuvo presente en la vida de Gaya. Fue esencial para entender el arte, la pintura y la creación, como se comprueba en la entrevista realizada por Elena Aub en 1981:

La música es importantísima para mí -hubiera sido la ilusión de mi padre- pero lo mío era la pintura y no me podía entretener en nada más. Pero lo musical para mí es importantísimo. (2007: 186)

Gaya no estudió música oficialmente, pero tocaba el piano de su casa de Valencia y poseía un violín que recibió como regalo de cumpleaños tras pintar Violín, para el cartel del VIII Aniversario del Museo Ramón Gaya. Su instinto natural para la pintura y la escritura también le fue útil para la música:

Me gusta sentarme al piano y buscar, tantear. Y ahora me decidí a comprar este piano y me ayuda muchísimo mientras estoy trabajando [...] lo único que sé es componer, bueno, como ahora me siento bastante al piano pues logro encontrar un tema y después puedo ir a buscarlo, puedo deshacerlo, hacer algunas variaciones, en fin. Instinto musical sí tengo. (2007: 186).

Gaya siempre fue un asiduo asistente a conciertos, lo que demuestra su gusto por la música, la importancia que esta tenía en su vida y su capacidad de disfrutar escuchándola. Manuel Fernández-Delgado rememora una anécdota que refleja 
claramente lo que Gaya sentía con la música en directo y de lo que era capaz de hacer para escuchar a los grandes intérpretes ${ }^{2}$.

Además, son numerosas las anotaciones que podemos encontrar en sus escritos en referencia a los conciertos o las óperas a las que asistía. Gaya fue un asiduo en teatros como «La Fenice» de Venecia, «El Liceo» de Barcelona o las Óperas de Roma y París. En su libro Diario de un Pintor resulta muy revelador que, en muchas ocasiones, la única anotación que aparece en el día es la asistencia a un concierto o a una ópera ${ }^{3}$.

\section{El sentimiento de la creación}

Para conocer el concepto de Ramón Gaya sobre el arte, hemos de adentrarnos en su primer libro, El sentimiento de la pintura (1960). En él, Gaya expone una clara distinción entre arte y creación, otorgando al creador un valor superior al artista. El arte es una voluntad del espíritu que representa la realidad, que se «disfraza» de ella y nace del pensamiento. Pero la creación va más allá, es la misma realidad y surge del sentimiento. Dado que este sentimiento se aferra a lo real, toda creación verdadera nace de la realidad. Solo así el creador puede sumarse a ella y alcanzar una comunión efectiva entre hombre y realidad:

El creador no es un hombre que construye cosas -como es un hombre que construye cosas el artista-, sino un hombre que espera, que cree, que cree en un alma de la realidad, y la espera [...]. El alma misma de la realidad quiere ser escuchada y, a su vez, escucharnos; para ello, para esa comunicación, nos propone algunos senderos materiales: la poesía, la pintura, la escultura y la música. (2010: 49-50)

\footnotetext{
${ }^{2}$ En 1981, en París, Gaya, Fernández-Delgado y otros acompañantes soportaron más de cuatro horas y media de espera en la cola de un teatro cercano a la Torre Eiffel, con la intención de conseguir entradas para el concierto que esa misma tarde ofrecía el gran violinista Pinchas Zukerman, «en el cual yo vi a Ramón Gaya llorar de emoción» (entrevista realizada por Pedro Sanz a Manuel Fernández-Delgado el 28 de junio de 2011 en el Museo Ramón Gaya).

${ }^{3}$ Muestro varios ejemplos de las anotaciones de Gaya en su diario: «1956. PARÍS, 10 de diciembre. Concierto en la Sala Gaveau [...] Mozart nos llega tan vivo, tan limpio, tan reciente»; «1957. ROMA, 16 de enero. Il ratto nel Serrallo, de Mozart, en la Ópera»; «1959. ROMA, 17 de enero. La Flauta Mágica»; «1963. ROMA, 3 de febrero. Vivaldi en La Cometa, con I Virtuosi de Roma»; «1963. ROMA, 21 de marzo. Concierto de I Musici»; «1963. BARCELONA, 22 de diciembre. La Clemencia de Tito de Mozart en el Liceo». Se encuentran, dentro de la Obra completa, en Diario de un pintor (1952-1953) y Retales de un Diario (1956-1963) (2010: 456-513).
} 
Gaya plantea cuatro puertas comunicantes por donde la realidad se abre paso. Se trata de cuatro formas de expresión (la pintura, la escultura, la poesía y la música) a las que identifica con los cuatro elementos naturales: pintura-agua, escultura-tierra, poesía-aire y música-fuego. Para Gaya, la naturaleza es única, inmensa, indivisible e inabarcable para el hombre. Pero este puede, a través de uno los cuatro elementos, llegar a los otros tres y, en consecuencia, a la totalidad, es decir, a través de una de las artes se puede llegar al sentimiento de la creación. Se trata de un sentimiento especial que solamente el creador percibe y le permite llegar hasta lo más profundo, hasta el alma de la realidad:

especie de jugosidad encerrada, contenida en la carne de la realidad; es como una sustancia interior, invisible, pero que a los ojos del pintor verdadero, nato, parece manifestarse, ofrecerse. Se diría que el pintor puede ver, por un milagroso acto de transparencia, esa «Agua» escondida como un tuétano. Porque el pintor la percibe, pero la percibe hundida, fundida en el cuerpo duro y hermético de la realidad, debajo de su hermosa corteza, latiendo, sí, pero no como un corazón, no como algo sensual, sino latiendo como un alma. (2010: 48)

Para Gaya, este sentimiento afecta al pintor, pero también, al poeta, al escultor y al músico:

para el escultor, esa alma era, decididamente, otra, no ya húmeda, tiernamente húmeda, sino autoritaria, firme, de «Tierra» material y ciega. Más allá veía al poeta, embriagado por el vívido soplo del «Aire» [...] Sólo me faltaba poder aceptar que la música dependiera del más fantasmal de los cuatro elementos; sí, fantasmal, ya que el «Fuego», aunque visible, no acababa de ser una presencia absoluta y, sobre todo, no logra...permanecer. (2010: 48-49)

Entre estas analogías, me gustaría resaltar esa idea de «no logra...permanecer». La música, como el fuego, nace, vive y... desaparece. La pintura, la escultura y la poesía quedan inmutables una vez pintado el cuadro, tallada la escultura o impreso el poema. En cambio, la música necesita del tiempo, es efímera: al terminar su interpretación ya no es. El músico podrá tocar una obra muchas veces, pero nunca será exactamente igual. Nunca conseguirá dos interpretaciones estrictamente iguales en su totalidad. Incidiendo en la dualidad creador-artista que nos plantea Gaya, la música necesita al compositor (el creador) y al intérprete (el artista). Una pintura, una escultura o una poesía, una vez finalizadas, quedan iguales para siempre. Una vez escrita, el compositor también deja para siempre una obra musical, pero para que 
esta pueda ser escuchada necesita a un intérprete que la haga renacer. Y cuando acaba su interpretación, al igual que el fuego, la música «no logra permanecer». Además, su aportación será esencial ya que, si fuera suficiente seguir las notas y las indicaciones que el compositor ha escrito, no existirían distintas versiones de una misma obra. $\mathrm{Y}$ las diferencias pueden ser realmente muy grandes. Cuando un oyente dice que prefiere la versión de una obra musical de un violinista o un director de orquesta concretos, está diciendo que el carácter, el tempo, la personalidad que proporciona dicho intérprete, son de su agrado más que las que aportan otros músicos. E incluso, como se comentaba anteriormente, una obra escuchada en directo interpretada por el mismo músico, pero en momentos distintos dará como resultado versiones con diferencias. De ahí esa idea de evanescencia, de fugacidad, de arte efímero que «no logra permanecer».

En la obra pictórica y literaria de Gaya se pueden establecer grandes ejes temáticos para encuadrar tanto las pinturas como los textos ${ }^{4}$. No se podrá abarcar aquí todo el material existente, pero se referirá lo más relevante, poniendo para ello determinados ejemplos que ilustren cada uno de los temas.

\section{Homenajes a Mozart}

Ramón Gaya sentía fascinación por Mozart, hasta el punto de que, para él, Mozart era la música. En su obra literaria encontramos numerosos ejemplos de la gran pasión que profesaba por su música. Las reiteradas referencias al compositor de Salzburgo en sus escritos desvelan que Gaya lo consideraba dentro del concepto de creador total:

Si no hubiese existido Mozart, yo mismo podría caer en la tentación de alejarme de la realidad y pasarme sin ella, a cambio de unos deleites sonoros; pero Mozart nos demostró que la música, la rigurosa caja de música, puede ser poblada, habitada sin ser destruida. (2010: 49)

Además de las continuas referencias de asistencia a conciertos y óperas mozartianas en Diario de un pintor, Gaya escribió Mozart durante su exilio en México a petición de su amigo músico Salvador Moreno. Gaya llevó a cabo este texto «porque se me hace a propósito de un nombre que me desarma: Mozart» (2010: 812). En él expresó sus sentimientos hacia la música de Mozart y declaró lo que el compositor significaba en su vida y en su forma de concebir el arte:

\footnotetext{
${ }^{4}$ En mi trabajo anteriormente citado, realicé tanto un exhaustivo y novedoso catálogo de temática musical de la obra pictórica de Ramón Gaya que incluye 110 obras, como una recopilación de sus escritos con contenido musical.
} 


\begin{abstract}
Mozart ha sido siempre para mí, más, mucho más que un músico; ha sido, me atrevería a decir, la música. Parece, más que ningún otro creador, un enviado monstruoso, una corporación humana de algo que no es, propiamente humano. Veo en él como en muy pocos, de tan absoluto que es, la gran inmoralidad del arte, la limpia, la pura, la alta inmoralidad que representa esa convivencia de lo celeste, diríamos, con lo terreno [...] está seguro de que haga lo que haga todo su interior irá filtrándose en la obra, quiera o no quiera. Ni la música misma parece importarle, ya que para él no es más que algo, diría yo, como su propio cuerpo.
\end{abstract}

México, 6 de agosto de 1944.

(2010: 812-813)

A lo largo de su obra pictórica, Gaya dedicó a Mozart siete homenajes. El primero de ellos data de 1951 y el último de 2000. Esto demuestra claramente que Mozart estuvo presente en la mente de Gaya durante toda su vida. Estos cuadros son: La partitura. Homenaje a Mozart (1951), II Homenaje a Mozart (1963), Homenaje a Mozart (1975), IV Homenaje a Mozart (1978), Homenaje a un Andante de Mozart (1980), Adagio (1989) y Homenaje a Mozart: El violín (2000).

Debido a la gran extensión en el tiempo de estas obras, podemos observar la evolución de la pintura de Gaya a través de ellas. Uno de los cambios evolutivos más significativos es que la pintura de Gaya ha ido diluyéndose paulatinamente a lo largo de los años. Las dos primeras obras son óleos con colores densos y oscuros, con gran cantidad de masa pictórica. A partir del tercer cuadro la paleta de Gaya se aclara, los colores se diluyen y los contornos se difuminan hasta llegar al último y más ligero de estos siete óleos. Esto también está presente en la forma de firmar las obras, pasando de incluir «Gaya», la fecha y el título del cuadro en sus primeras obras, a una simple «G.» y la fecha en la última. Podemos deducir que este proceso de abreviación se debe a la dificultad visual y táctil que a sus noventa años le suponía escribir en los lienzos.

Todos los homenajes a Mozart son bodegones, naturalezas muertas, pinturas sobre objetos comunes que Gaya tenía en su casa o en su estudio, a los que añadía algún elemento musical que simbolizara el homenaje, tales como partituras, un violín o el piano del pintor. Además de estos elementos claramente evidentes, en el tercer y cuarto lienzos Gaya muestra una jaula de pájaros como símbolo musical, sugiriendo un guiño al personaje de Papageno de La Flauta Mágica ${ }^{5}$ de Mozart. En sus homenajes, Gaya pretendía señalar que el arte, representado por la reproducción

\footnotetext{
${ }^{5}$ La Flauta Mágica es la última ópera de Mozart, compuesta en el mismo año de su muerte, 1791. El personaje de Papageno (barítono) es el principal personaje cómico de la trama, un pajarero que ayudará al príncipe Tamino en sus aventuras. Papageno aparece con traje de plumas y una jaula en la que lleva a sus pájaros.
} 
de la obra del artista homenajeado, o en estos casos los símbolos musicales, sucede en medio de la vida, representada por los objetos cotidianos, los libros, las flores, los muebles (se puede leer en la entrevista realizada por Nigel Dennis en 1983):

Es verdad que me interesa mucho más un objeto anónimo, sin valor artístico - un objeto común, un objeto de la vida, de la vida común, completamente- que un objeto destacado, un objeto de museo. (2007: 241)

En estos homenajes, como en la mayoría de sus obras, Gaya pintó su característica copa o jarra con flores. En la entrevista concedida, conversó sobre el cristal y lo que significaba para él su transparencia:

A mí me bastaba con saber que esa transparencia me gustaba, que esa transparencia no era para mí solamente una maravilla, un fenómeno maravilloso, sino que me llevaba a otras cosas -a ver, por ejemplo, los objetos a través de esa transparencia [...]. Muchas veces he puesto frutos o flores detrás de esos vasos. No ya unas flores dentro de un vaso sino detrás de un vaso. Y resulta que esas flores quedan...transformadas. Es decir que un cristal se abre sobre un abismo: el abismo de la transparencia [...] esa transparencia del cristal era como una metáfora [...] una metáfora de la realidad misma. Es decir, para mí, la realidad tiene cuerpo, tiene presencia, y además es al mismo tiempo transparente. Detrás de la realidad parece que se divisa algo, que se ve algo [...] a mí, quizá, me atrae mucho el cristal o las cosas de vidrio, porque las veo como una metáfora de eso, de esa idea que tengo de la realidad... (2007: 241-242)

Creo firmemente que esa copa, con el paso de los años, se convirtió en un símbolo de Gaya, en una seña de identidad, en un icono que representa al propio pintor.

\section{La amistad con Victoria de los Ángeles}

Victoria de los Ángeles López García (1923-2005) fue una de las voces españolas de más reconocido prestigio del siglo XX y durante su dilatada carrera actuó en los escenarios más importantes del mundo. La cantante y Gaya se conocieron a través de Salvador Moreno y siempre mantuvieron una gran relación de amistad. Gaya asistió a gran número de conciertos y recitales en los que ella interpretó asiduamente el Soneto de este, Al silencio, al que Moreno puso música.

En Carta a un músico amigo sobre Victoria de los Ángeles podemos apreciar la devoción de Gaya hacia la cantante, a la que consideraba dentro de su concepto 
de creador, junto a sus ideas en torno a las artes y a la música. Este texto destinado a Salvador Moreno se incluye en Milagro Español, obra en la que Gaya expresa su admiración y elogios hacia algunas figuras artísticas y literarias españolas como Galdós, Picasso, Falla, Pastora Imperio, Zurbarán o Don Quijote:

Ya sabes que desde hace mucho vengo acariciando la idea de escribir unas páginas sobre la muy sutil y vigorosa singularidad de Victoria de los Ángeles, o más exactamente, sobre ese... milagro musical suyo [...].

La relación, la comunicación de Victoria de los Ángeles con la música (como ya te dijera, hace años, en Roma, donde la oímos juntos) no es sólo una relación de intérprete, de gran intérprete, sino de... creador, y no porque altere la escritura de Haendel, Mozart, Schubert, Massenet, Debussy, sustituyéndola con una invención propia, sino porque, antes de tropezarse con la escritura de éstos, parece como si se hubiese tropezado ya con ellos en... la música, en la concavidad de la música, en donde habita la pura y sola música -pues no hay más que una-; se encuentra con ellos, diríamos, allí, y ya con ellos, con cada uno de ellos, y junto con la música que ha ido, como ellos, a recoger en la fuente misma, primordial, de la música, puede venir hasta nosotros para darnos, no una versión -no una interpretación- de tal lied de Schubert o del Porgi amor de Mozart, sino algo, diríase, como una... totalidad.

Madrid, 1985.

(2010: 168-170)

Desde 1959 hasta 1998, Gaya pintó nueve obras dedicadas a Victoria de los Ángeles. Varias de ellas son retratos, otras son dibujos que sirvieron para ilustrar carteles de conciertos de la soprano y otras son bodegones, en el mismo estilo de los homenajes a Mozart, en los que aparecen sus típicas jarras o copas con flores. De estos cuadros me gustaría destacar dos: el primero de todos ellos, Retrato de Victoria de los Ángeles (1959), pintado en Roma y actualmente ubicado, a petición de la cantante, en el Museo Ramón Gaya de Murcia, y Homenaje a Victoria (Fabritius) (1996), en el que, además de un retrato de ella, al igual que en los homenajes a Mozart, Gaya pintó una jaula y un pájaro como símbolos musicales, aunque esta vez el pájaro no está dentro de la jaula sino que Gaya pinta una reproducción de $E l$ Jilguero, el cuadro de Carel Fabritius que más admiraba.

Además, en marzo de 1994, el Museo Ramón Gaya organizó un encuentro entre Ramón Gaya y Victoria de los Ángeles en Murcia, en el que se expusieron los cuatro homenajes depositados en dicho museo, junto a la partitura de Al silencio. 


\section{Salvador Moreno, el músico amigo en el exilio}

Salvador Moreno Manzano (1916-1999), mexicano de padres españoles, fue músico, compositor, director de orquesta y crítico musical. Gaya lo conoció en 1939, durante su exilio en México y mantuvieron una gran amistad durante toda su vida. Entre sus composiciones para voz destacamos, como hemos visto anteriormente, Al silencio, segundo poema de los Seis sonetos de un diario (2010: 615-619), que Ramón Gaya escribió en México en 1939, al que Salvador Moreno puso música en 1954, y que Victoria de los Ángeles interpretaba frecuentemente. Además, en 1943 Salvador Moreno planeó escribir una ópera titulada El Pintor Fausto, con libreto de Ramón Gaya, aunque la obra nunca se realizó.

En 1980, la partitura de Al Silencio formó parte del Homenaje a Ramón Gaya (1980), libro publicado el 10 de octubre de dicho año como un sentido tributo de amigos y admiradores de Gaya en su septuagésimo aniversario. Leemos (2010: 616):

\section{AL SILENCIO}

No es consuelo, silencio, no es olvido

lo que busco en tus manos como plumas;

lo que quiero de ti no son las brumas, sino las certidumbres: lo perdido.

Con toda su verdad, lo que escondido hoy descansa en tu seno, las espumas de mi propio sufrir, $\mathrm{y}$ hasta las sumas de las vidas y muertes que he vivido.

No es tampoco el recuerdo lo que espero de tus manos delgadas, sino el clima donde pueda moverme entre mis penas.

No esperar, mas tampoco el desespero. hacer, sí, de mí mismo aquella sima en que pueda habitar como sin venas.

En este mismo libro, Salvador Moreno escribió Desde México, en torno a Ramón Gaya (1980: 87-92), texto en el que describe cómo se conocieron y la amistad que les unió. A su vez, a lo largo de su obra literaria, Gaya escribió tres textos dedicados a Salvador Moreno. El primero de ellos es El extremoso deber del artista, de 1940 
(2010: 269-272), en el que Gaya reflexiona sobre el compromiso y los deberes que el creador de arte asume en su vida. El segundo es Anotaciones (en programa de concierto), de 1951 (2010: 821), publicado en el programa de mano del concierto benéfico de despedida de Salvador Moreno, celebrado en México en octubre de 1951, en el que Gaya elogia la sensibilidad, el talento y el instinto musical de su amigo. El tercer texto, aunque no se cita su nombre, es como ya hemos visto, Carta a un músico amigo sobre Victoria de los Ángeles (2010: 168-170).

Además, ambos mantuvieron durante años correspondencia epistolar. En Cartas de Ramón Gaya (a Tomás Segovia, Salvador Moreno, Rosa Chacel y María Zambrano), encontramos trece cartas que Gaya envió a Salvador Moreno entre mayo de 1956 y junio de 1961 (1993: 49-99).

En cuanto a su obra pictórica, Gaya realizó seis obras dedicadas Salvador Moreno. Tres retratos del músico en la etapa mexicana del pintor, entre los que destacamos Salvador Moreno pintando (1950) y tres ilustraciones con motivos musicales, una para Cartas de Ramón Gaya y dos para El sentimiento de la música $(1986)^{6}$. Este libro de Moreno está ilustrado totalmente por dibujos de Gaya y su título hace una clara referencia a El sentimiento de la pintura que, como hemos visto, Ramón Gaya había escrito en 1960. El primer dibujo presenta el capítulo El sentimiento de la música en Picasso y muestra una guitarra Picassiana y una partitura sobre una mesa, a modo de bodegón cubista. El segundo dibujo aparece en la portada del capítulo Cosi fan tutte de Mozart y representa a los dos personajes femeninos de dicha ópera, Dorabella y Fiordiligi.

\section{Los homenajes a Stravinsky y a Picasso}

Stravinsky y Picasso fueron para Gaya las dos figuras más interesantes y representativas del siglo XX. Gaya admiraba el estilo «neoclásico» de Stravinsky, su «retorno» a la música del periodo clásico como contraste ante el subjetivismo del movimiento romántico y del expresionismo. En el ejemplar de Poética musical $(2006)^{7}$ de Stravinsky que Gaya conservaba en su archivo particular, se observan

\footnotetext{
${ }^{6}$ Salvador Moreno habla de la música en torno a temas y personajes tan dispares como El Quijote, San Juan de la Cruz, Mozart o Picasso. El capítulo titulado El silencio de la Música en San Juan de la Cruz está dedicado a Victoria de los Ángeles y el que lleva por nombre Così fan tutte de Mozart, a Ramón Gaya.

${ }^{7}$ Esta obra reúne las seis conferencias que Stravinsky dio en la Universidad de Harvard, en la que ocupaba la Cátedra de Poética, durante el año académico 1939-1940. En ellas Stravinsky expuso sus ideas sobre la creación, la composición y la ejecución de la música, en una profunda reflexión sobre el fenómeno musical.
} 
anotaciones de puño y letra del pintor y pasajes subrayados que muestran las ideas por las que admiraba al músico: la vuelta a lo antiguo y a la tradición como forma de progreso para asegurar la continuidad de la creación.

De nuevo en Diario de un Pintor aparecen las anotaciones de Gaya sobre su asistencia a conciertos en Venecia dirigidos por Stravinsky, en el Teatro de «La Fenice» y en la iglesia de San Rocco ${ }^{8}$.

Además, Gaya dedicó tres obras al compositor. Stravinsky en La Fenice (1958) es un pequeño dibujo a bolígrafo del músico dirigiendo en el concierto que Gaya menciona en su diario. Homenaje a Stravinsky (1983) es un bodegón en el que el pintor utiliza una paleta fría de colores. Y Homenaje a Picasso y a Stravinsky (1978) es un tributo conjunto cargado de simbología. En él, Gaya reproduce la partitura de Stravinsky Los cinco dedos; el dibujo que Picasso había hecho del músico en 1920; un dibujo cubista en el que podemos ver la «f» de un instrumento de cuerda; una jaula como símbolo musical, al igual que en los homenajes a Mozart; y la siempre presente copa de cristal.

Los homenajes a Picasso y al cubismo fueron constantes en la obra de Gaya. En 1953 Gaya reflejó su entusiasmo por el pintor en Milagro español:

Picasso es, sin duda, uno de los más grandes milagros españoles [...] seguir a Picasso (y tenemos la obligación de seguirle, puesto que parece haberle sido encomendada la clave del presente) no consiste, como han supuesto tantos, en imitarle, sino en volver a tomar la Pintura exactamente donde él la interrumpió. (2010: 152-153)

Influido por Picasso, Gaya realizó en su primera época varios cuadros cubistas, aunque pronto abandonó el uso de las vanguardias para desarrollar su propio estilo pictórico. Pero los homenajes a Picasso y al cubismo estuvieron siempre presentes. Gaya pintó once de estas obras, naturalezas muertas en las que plasmaba, a la manera de Picasso, algún instrumento musical como guitarras y violines o reproducía estampas cubistas con fragmentos de ellos. Entre todos estos homenajes destaco Autorretrato con el primer homenaje al cubismo (1986), en el que vemos el retrato de Gaya reflejado en un espejo, junto a una estampa cubista con una guitarra y la copa de cristal.

\footnotetext{
8 «1958. LA SERENISSIMA, 19 de septiembre. Concierto de Stravinsky en la Fenice»; «1958. LA SERENISSIMA, 23 de septiembre. Concierto de Stravinsky en San Rocco. Las lamentaciones de Jeremías» (2010: 480 y 481).
} 


\section{El flamenco}

Gaya siempre se interesó por el flamenco. Lo identificaba como algo muy valioso. Tras su exilio en México, encontró en él una manera de reencontrarse con lo español. De nuevo aparecen en su diario anotaciones de su asistencia, esta vez a tablaos y recitales flamencos, en las que incluía nombres de artistas que le habían impresionado?.

En 1953, en Milagro Español, Gaya escribió dos textos relacionados con el flamenco: Pastora Imperio, en el que refleja su entusiasmo por esta bailaora, y Manuel de Falla, en el que otorga al compositor español, gran amante y conocedor del flamenco, en especial del cante jondo, la condición de creador, alabando su consecución de un lenguaje propio y auténtico:

Pastora salió a escena con su famoso brazo en alto y en esa postura erguida, desafiante, típica del flamenco y que no constituye propiamente paso de baile alguno; no es, todavía, baile, sino acaso lugar, el lugar, la creación del lugar en donde el baile va a suceder [...] Me di cuenta en seguida de que estaba delante de algo irrepetible; comprendí que en Pastora no se trataba de bailar muy bien, extraordinariamente -antes, quizá, ya se había bailado como ella y quizá incluso mejor que ella-, comprendí que no se trataba de hacer, sino, de ser. Pastora es irrepetible, no en la medida que es irrepetible algo, sino alguien. Eso que ella bailó, aunque se bailara igualmente bien, sin Pastora no sería más que baile, porque cuando algo ha sido habitado así, después se vacía, se vacía sin remedio. (2010: 146-147)

Falla es, quizá, el músico que termina con lo popular, que rompe definitivamente con lo popular [...] adentrándose en ello para libertarse de ello, y lo que es más importante, para dejar libre de él, del músico que es él, del creador que es él, a lo popular [...] para ir hacia una naturalidad propia, hacia una autenticidad de la cual podamos ser responsables. Ese ha sido su genio [...] Falla supo comprender su tarea genial, y cumplirla con heroísmo. (2010: 178-179)

Gaya realizó más de cuarenta obras relacionadas con el flamenco. Es la serie más amplia y abarca toda su carrera pictórica desde 1940. La gran mayoría son dibujos a lápiz, tinta, o gouache en los que Gaya pintó imágenes flamencas como bailaores, cantaores o guitarristas, algunas de las cuales han servido para ilustrar libros de temática musical o carteles de festivales como el Festival del Cante de las Minas de

${ }^{9}$ «1959. MADRID, 12 de mayo. Por la noche, Rosita Durán, Varea, Romero, Pericón de Cádiz»; «1961. ROMA, 29 de abril. Cante y baile: Manuela Vargas. El Güito. Enrique el Cojo. Jarrito» (2010: 489 y 595). 
La Unión. De todo este gran conjunto, y a colación del texto anterior, destacaré las tres que dedicó a Pastora Imperio.

Pastora Imperio (1968) es un dibujo lleno de vitalidad en el que Gaya ilustra con un primer trazo muy claro la figura de la bailaora, añadiendo de forma más difusa una serie de ligeros esbozos que simulan los movimientos de los brazos de la artista, para conseguir un juego visual que resalta la plasticidad de su baile.

Homenaje a Pastora Imperio (1989) y Retrato de Isabel (1990) son los únicos óleos de la serie. El primero es una naturaleza muerta en la que aparece una estampa de la bailaora para realizar el homenaje. El segundo es un curioso cuadro en el que el personaje y elemento principal de la obra es Isabel Verdejo pero, detrás de ella, Gaya reprodujo una foto de Pastora Imperio hecha en 1933, en la época en la que la vio actuar, tal y como escribió en el texto de Milagro español.

\section{Il Tempo}

Gaya pintó nueve obras en las que aparece un metrónomo. Este elemento es usado por los músicos para establecer el «tempo» musical, la velocidad y el ritmo de las partituras interpretadas. El metrónomo de Gaya alude, no solo a este «tempo» musical, sino también a la fugacidad del tiempo y de la vida. Estos cuadros son bodegones, en los que el metrónomo aparece junto a enseres comunes y otros elementos musicales como partituras o el piano que Gaya tenía en su casa, creando así obras con gran carga de simbología musical.

De todas ellas destacaré cuatro: la primera de la serie, Autorretrato con metrónomo (1979), en la que aparece el retrato del pintor reflejado en un espejo; Il Tempo (1988), la obra que por su título mejor resume este concepto; Homenaje a Luis Cernuda (1988), en la que Gaya reproduce uno de sus cuadros preferidos, el óleo de Murillo Niños comiendo melón y uvas; y El metrónomo y la taza (2001), la última obra de mi catálogo, la última pintura de temática musical que hizo Ramón Gaya. Es una pintura limpia y clara en la que tan sólo aparecen el metrónomo y la taza apoyados sobre el piano.

Además, el «tempo» es un concepto fundamental en música, pero también en poesía, por lo que el metrónomo tiene una doble función, musical y poética:

Un poema de Cernuda, aparte de lo que nos dice, de tener una gran profundidad aquello que nos dice, es en sí mismo muy poético, muy lírico. Su verso se sostiene por sí mismo, y se sostiene porque tiene la curvatura que debe tener un verso. (2007: 233) 


\section{El piano de Gaya}

Uno de los instrumentos más representados por Gaya es el piano de su estudio. Además de los ejemplos descritos en anteriores apartados, Gaya realizó una serie de obras, en su mayoría naturalezas muertas, en las que pintó sus objetos cotidianos apoyados sobre el piano. Destacaré de nuevo cuatro de ellas.

Homenaje a Nietzsche y autorretrato en el piano (1981) está dedicado al filósofo Friedrich Nietzsche, al que Gaya comenzó a leer en la colección de libros de su padre. Vemos el autorretrato reflejado en el piano y sobre él una carta autógrafa de Nietzsche que Gaya compró en París en 1952. En el piano (1989) es la única que no es un óleo, sino un pequeño dibujo a bolígrafo en el que aparece Isabel Verdejo tocando el piano y, sobre el instrumento, un vaso y una copa.

Las dos obras siguientes son homenajes a dos pintores. Gaya siempre tuvo en su estudio reproducciones de cuadros rodeadas de libros, flores, copas... Especialmente durante su exilio en México, en donde no podía visitar los museos a los que tanto le gustaba ir para ver las obras de los grandes maestros de la pintura:

Para mí era un gusto vivir entre esas reproducciones que tenía en el estudio [...] lo que hacía era señalar algo que era una pena que se perdiera, que era una pena que la gente estuviera de espaldas a cosas que forman parte de nuestra vida, que son nuestro propio presente... (2007: 239-240)

En Homenaje a Ensor (1990) el piano no es el elemento central, sino que Gaya reprodujo el óleo de James Ensor La música rusa, en el que una mujer de espaldas toca el piano junto a un hombre que escucha su interpretación. Resulta muy revelador que para este homenaje Gaya eligiera este cuadro de temática musical y no cualquier otro del autor. Homenaje a Van Gogh y piano (1992) es una de las numesosas obras que Gaya dedicó a uno de sus pintores más admirados. Vemos una partitura en el atril del piano y sobre él, una reproducción del óleo de Van Gogh Jardín de Daubigny.

\section{Guitarras}

Gaya representó guitarras y otros instrumentos similares de cuerda pulsada en varias de sus obras. Bodegón (1926), El Bodegón de la mandolina (1927) y Maja (1928) son las pinturas musicales más antiguas de Gaya. La primera posee una perspectiva muy original en la que la guitarra aparece sobre una mesa de forma perpendicular al espectador. La segunda es una pintura en la que aún podemos ver 
muy claramente la influencia cubista del primer Gaya que, como he comentado con anterioridad, abandonaría muy pronto para crear su propio lenguaje pictórico. La tercera es un gouache en el que una mujer, sentada en una silla, toca una guitarra.

Otras obras con guitarras sirvieron para ilustrar portadas de libros e incluso partituras musicales. Es el caso Viñeta para «Barrio de Córdoba» (1938), un dibujo de una figura femenina tocando una mandolina que ilustra Barrio de Córdoba (Tópico Nocturno $)^{10}$, una pequeña obra para piano en la que Julián Bautista puso música al poema del mismo nombre de Federico García Lorca. En cuanto a los libros, Guitarra para imágenes de la música iberoamericana (1992) es un dibujo de una guitarra, una partitura y una copa que aparece en Imágenes de la música Iberoamericana. El arlequin y la bandurria (1993) ilustra Versos y Canciones. Y Sin titulo (1993) es un dibujo del contorno de una guitarra y una partitura que se encuentra en Otro tiempo.

\section{Música y danza}

La música también está presente en la obra de Gaya a través de la danza. Para homenajear a Edgar Degas, Gaya eligió la escultura de su célebre Bailarina que podemos encontrar en el Museo de Orsay de París. Como he comentado con anterioridad, a Gaya siempre le gustó visitar los principales museos europeos como el Museo del Prado de Madrid o el Museo del El Louvre de París, y contemplar in situ el arte de los maestros que más admiraba.

Diez obras componen esta serie: cuatro pequeños dibujos a lápiz y seis gouaches. Excepto una, todas representan visitantes del museo que están admirando la bailarina, como Escultura de Degas en el Jeu de Pomme (1978), o que fijan su atención en otras obras cercanas, como Bailarina de Degas (Museo de Orsay) (1992), Homenaje La Bailarina de Degas (1992) o La Bailarina de Degas (1995). Incluso en varias de ellas, su título no hace referencia a la bailarina sino a los espectadores, como Las dos señoras (1992) y Los Visitantes (1992).

En Bailarina de Degas y cuadro de Manet (1992), Gaya homenajea a ambos artistas reproduciendo el óleo de Manet La Dama de los abanicos, Madame Nina de Callias. Los abanicos siempre fueron un objeto muy del gusto de Gaya y aparecen frecuentemente representados en sus pinturas.

La única obra de esta serie en la que la escultura de la bailarina aparece aislada, en primer plano, sin estar expuesta a los ojos de los visitantes del museo, es $L a$ Bailarina de Degas (1992). También es la única en la que Gaya firmó incluyendo el nombre del pintor francés: «De Degas. Gaya 92».

10 Bautista, J. y García Lorca, F. (1938), Partitura de "Barrio de Córdoba. (Tópico Nocturno)". Suplemento de Revista Música, n. ${ }^{\circ} 1$ (enero). 


\section{Pinturas para carteles}

Como se ha podido comprobar en ejemplos anteriormente expuestos, algunas obras de Gaya fueron pensadas o utilizadas para ilustrar carteles de conciertos y festivales. Beethoven (1977) ilustró el cartel del concierto de la Asociación ProMúsica de Murcia «Homenaje a Beethoven» por el 150 aniversario de su muerte, celebrado el 18 abril de 1977 en el Teatro Romea de Murcia, a cargo del pianista Hans Ritcher Haaser. Napolitana (1985) protagonizó el del XVIII Festival Internacional Folklore del Mediterráneo (Murcia, 4-15 de septiembre de 1985) y Tuno (1997) el del X Certamen Internacional de Tunas «Costa Cálida 97» (Murcia, 31 de marzo-4 de abril de 1997).

Además, como apunté al comienzo de este artículo, Violín (1998) fue un encargo del Museo Ramón Gaya para el cartel que celebraba su VIII Aniversario. Es un gouache con un violín, su arco y una copa de cristal. El arco del violín «atraviesa» la copa, creando un juego de perspectivas en el que Gaya muestra su magistral dominio de las transparencias.

\section{Otras temáticas}

Existen otras obras de Gaya que no se ajustan a ninguna de las temáticas anteriormente descritas, de entre las cuales destacaré dos. En el palco de la Scala (1966) es un dibujo a lápiz sobre el programa de mano de un concierto en Teatro de «La Scala» de Milán al que Gaya asistió. En El violinista Pinelli (de Rosales) (1998) Gaya realizó un homenaje al pintor Eduardo Rosales, reproduciendo el retrato que este hizo del violinista Ettore Pinelli, junto a una partitura y una copa.

\section{Conclusiones}

A lo largo de este artículo he demostrado la gran importancia que tuvo la música en la vida y en la obra de Ramón Gaya. Se ha analizado su pensamiento artístico y sus escritos y pinturas de temática musical, poniendo de manifiesto la gran cantidad de obras y textos musicales que Gaya pintó, dibujó y escribió.

La música fue para Gaya un elemento esencial a la hora de entender el arte y un camino fundamental para alcanzar el sentimiento de la creación. Fue aficionado a tocar el piano, asiduo asistente a conciertos y mantuvo dilatadas amistades con grandes músicos. 
Su pensamiento en torno a la música y a los músicos ha quedado reflejado en algunos de sus trabajos literarios como El sentimiento de la pintura, El extremoso deber del artista, Mozart, Anotaciones (en programa de concierto), Manuel de Falla, Pastora Imperio y Carta a un músico amigo sobre Victoria de los Ángeles.

Las principales temáticas musicales en que se encuadran sus textos y sus pinturas son: homenajes a Mozart; obras dedicadas a sus amigos músicos Victoria de los Ángeles y Salvador Moreno; homenajes a Stravinsky y Picasso; el flamenco; pinturas con elementos musicales como metrónomos, el piano de su estudio o guitarras; la danza a través de sus obras dedicadas a la bailarina de Degas; y pinturas para carteles de conciertos y festivales.

Como se apuntaba al comienzo de este artículo, Gaya fue un creador completo, un hombre del Renacimiento que vivió, sintió y creó arte en muchas de sus manifestaciones. Y la música siempre estuvo presente, fusionada con la pintura, con la literatura, con la poesía, en la obra y en la vida de un creador en el que las artes se entremezclan formando un todo pleno.

\section{Bibliografía}

Auden, Wystan Hugh, Otro tiempo, Valencia, Editorial Pre-textos, 1993.

Cobos, Pedro, Versos y Canciones, Murcia, Editora Regional de Murcia, 1993.

Franco, Enrique (ed.), Imágenes de la Música Iberoamericana, edición especial Quinto Centenario, Santander, Fundación Isaac Albéniz, 1992.

Gaya, Ramón, El sentimiento de la Pintura, Madrid, Arión, 1960.

Gaya, Ramón, Cartas de Ramón Gaya (a Tomás Segovia, Salvador Moreno, Rosa Chacel y María Zambrano), Murcia, Ayuntamiento de Murcia/Museo Ramón Gaya, 1993.

Gaya, Ramón, Ramón Gaya de viva voz. Entrevistas (1977-1998), selección y presentación de Nigel Dennis, Valencia, Editorial Pre-textos, 2007.

Gaya, Ramón, Obra completa, ed. de Nigel Dennis e Isabel Verdejo, Valencia, Editorial Pre-textos, 2010.

Moreno, Salvador, El Sentimiento de la Música, Valencia, Editorial Pre-textos música, 1986.

Stravinsky, Ígor, Poética Musical, Barcelona, Acantilado, 2006.

VV.AA., Homenaje a Ramón Gaya, Murcia, Editora Regional de Murcia, 1980. 